\title{
Completing the demographic transition
}

John Bongaarts

Population Council

Rodolfo A. Bulatao

Follow this and additional works at: https://knowledgecommons.popcouncil.org/departments_sbsr-pgy

Part of the Demography, Population, and Ecology Commons, Family, Life Course, and Society Commons, and the International Public Health Commons How does access to this work benefit you? Let us know!

\section{Recommended Citation}

Bongaarts, John and Rodolfo A. Bulatao. 1999. "Completing the demographic transition," Policy Research Division Working Paper no. 125. New York: Population Council. Version of record: https://doi.org/ 10.1111/j.1728-4457.1999.00515.x 


\section{Completing the $D$ emographic Transition}

John Bongaarts

Rodolfo A. Bulatao

1999 No. 125 


\title{
Completing the Demographic Transition
}

\author{
John Bongaarts \\ Rodolfo A. Bulatao
}

John Bongaarts is Vice President, Policy Research Division, Population Council, New York. Rodolfo A. Bulatao is Study Director, Panel on Population Projections, Committee on Population, National Academy of Sciences, Washington, DC. 


\begin{abstract}
Despite ongoing declines in fertility in many countries, the population of the world is experiencing a period of rapid expansion, and its size is expected to exceed 10 billion by the end of the demographic transition. Three causes of this growth are identified and quantified: 1) fertility above the replacement level of two surviving children per woman, 2) continuing declines in mortality, and 3) population momentum resulting from a young age structure. A set of simple analytic expressions is proposed for estimating these factors from standard demographic indicators. Population momentum is shown to be the main cause of future growth in most countries and regions.
\end{abstract}

This material may not be reproduced in any form without written permission from the authors. 
Over the past century virtually all countries have made rapid progress through their demographic transitions, as reflected in large declines in birth and death rates. Population growth has been rapid, because reductions in death rates preceded declines in birth rates. The population size of the world increased from 1.6 billion in 1900 to 2.5 billion in 1950 and to 6.1 billion at the end of this century. The populations of the industrialized world (the "North") have essentially completed their transitions, ${ }^{1}$ and, even including immigration, the average rate of population growth in the North is only a fraction of one percent per year. In contrast, in much of the developing world (the "South"), population growth continues at a high pace, despite substantial reductions in fertility over the past several decades.

Projections made by the United Nations and the World Bank assume all countries will complete their demographic transitions over the next century. Population size for the world as a whole is expected to rise to 10.4 billion by 2100 according to the UN (1998a) and to 10.0 billion according to the World Bank (1998). Virtually all of this increase is expected to occur in the South, with the North remaining close to its current size. Projections made by other agencies (e.g., IIASA (Lutz 1996) and US Bureau of the Census (1999)) give similar results. At the country and region level, projected changes in population size over the next century vary widely. In some African and Asian countries populations are projected to more than triple in size, while declines in population size are expected for some countries in the North.

Future trajectories in population size are determined by future trends in fertility, mortality, and migration and by the current distribution of population by age. The objective of this paper is to propose a procedure for quantifying these four components of future population growth. The contributions attributable to the different factors are first measured by making a set of hypothetical projections for countries and regions. In the second part of the paper, simple analytic expressions are provided to estimate the impact of changes in factors from trends in fertility, mortality, and age structure, so that their role can be calculated with- 
out making population projections. This analysis is not intended to evaluate the accuracy of existing projections. Our main aim here is to improve understanding of the demographic factors that determine long-range population growth by quantifying how much of a projected change in population is due to assumed trends in the different determinants.

\section{Why POPUlation GroWth Continues}

The future growth expected for the world and most regions and countries is attributable to four factors:

\section{Fertility above replacement}

Fertility is at replacement when each generation of women exactly replaces the previous one (i.e., the average newborn girl gives birth to one daughter over her lifetime). Replacement is a critical factor in population projections because it equals the fertility level that, if maintained over time, produces zero population growth. ${ }^{2}$ Positive or negative deviations from replacement lead in the long run to persistent population growth or decline, respectively. Currently, replacement fertility equals 2.4 births per woman in the South and 2.1 in the North. These levels exceed 2 because children who die before reaching the reproductive ages have to be replaced with additional births, and because the sex ratio at birth slightly exceeds one (typically 1.05 males for every female birth). Despite rapid recent declines in many countries, fertility in 1995-2000 remains well above the replacement level in most regions in the South, ranging from a high of 5.1 in Africa to 3.4 in South Asia and 2.7 in Latin America (UN 1998b). This implies that fertility remains one of the key forces contributing to further growth in the South. In contrast, fertility is now below replacement in Europe (1.4), Northern America (1.9), and East Asia (1.8).

Projections typically assume that future fertility will decline in countries where it is above replacement, eventually stabilizing at the replacement level 
before 2025 in Asia and Latin America and before 2050 in Africa. In countries where fertility is now below replacement (mostly in the North), it is usually assumed to rise back to the replacement level eventually. Maintaining fertility at replacement assures that population growth reaches zero at the end of the transition (if mortality stops changing and migration is zero). The future trajectory of population size is highly sensitive to deviations of fertility from the replacement level.

\section{Declining mortality}

Rapid declines in mortality have been the main cause of population growth in the past. Global life expectancy at birth now stands at 65 years, more than double the pretransitional level of about 30 years (UN 1998b). Since the middle of the twentieth century, the South has experienced exceptionally rapid improvements in life expectancy, which has risen from an average of about 40 years in 1950 to 63 years today. Latin America has reached life expectancy levels similar to those prevailing in the North in the 1960s, and Asia is not far behind. Africa's mortality has been highest, resulting in a current life expectancy of 51 years. In the North, mortality was already low in the 1950s, but life expectancy has continued to rise, reaching 75 years today.

Over the next century, projections made by the UN and World Bank assume life expectancy to continue to rise in all regions. By 2025 Asia and Latin America are both expected to have mortality conditions similar to those in the North today, but Africa will continue to lag, in part because the continent is the one most heavily affected by the AIDS epidemic. Achieving further reductions in mortality may become more difficult as countries reach ever-higher levels of life expectancy. Maximum life expectancy for all populations is assumed to be the same, at 87.5 years for males and 92.5 for females by the UN (1998a) and at 83.3 years for males and 90 for females by the World Bank. All countries are expected to be close to these maxima by the middle of the twenty-second century. Whether higher values are possible for the average human life span is the subject of an ongoing debate. 


\section{Net immigration}

In the past, net migration has been substantial toward some countries, e.g., the United States, and out of other countries, e.g., Mexico, but negligible in others. Large differences in migration levels among countries are likely to be observed in the future. At the world level migration is necessarily zero.

\section{Young age structure}

Even if fertility could immediately be brought to the replacement level with constant mortality and zero migration, population growth would continue in many countries, particularly in the South. The reason for this is a young age structure, which is the result of high fertility and low mortality and consequent rapid population growth in recent decades. With a large proportion of the population under age 30, further growth over the coming decades is assured. The relative abundance of these young people results in a birth rate that is higher than the death rate even if fertility is at replacement. This age-structure effect is called population momentum ${ }^{3}$ (Keyfitz 1971).

\section{Components of Future Population Growth}

Future population growth will continue as long as one or more of the following conditions are met: fertility remains above replacement, life expectancy keeps rising, net immigration is positive, and the population age structure is young relative to its equilibrium structure. In population projections made by the UN, the World Bank, and other agencies it is usually assumed that at the end of the transition each of these factors will have moved to levels where they no longer contribute to population growth. That is, fertility moves to the replacement level, life expectancy to its presumed maximum, migration to zero, and the age structure to its post-transitional equilibrium (which depends on the mortality pattern). This set of assumptions conveniently ensures zero population growth, but there 
is, of course, no assurance that this in fact will happen. We return to this issue in a later section, but for now we accept this convention.

The contribution of each of the preceding demographic factors to future population growth can be estimated with a simple series of hypothetical projections. In these projections, the influence of one factor is removed at each successive step. The starting point is a standard projection, which is determined by all four factors. The next step in this exercise is to estimate the future growth that would occur if migration is set to zero from 2000 onward. The resulting projection variant will be called natural. In a third variant the effect of fertility deviations from replacement is also removed by setting fertility at the replacement level from 2000 onward (still keeping migration zero). This is the replacement projection. In the fourth and final variant, mortality is held constant as well from 2000 onward. This momentum projection reflects only the effect of a young age structure in 2000. In sum:

\section{Projection}

variant

1. Standard

2. Natural

3. Replacement

4. Momentum
Factors affecting future growth

Young age structure, rising life expectancy, fertility above replacement, net immigration

Young age structure, rising life expectancy, fertility above replacement

Young age structure, rising life expectancy

Young age structure
Projected

population size

$\mathrm{P}_{\mathrm{s}}$

$\mathrm{P}_{\mathrm{n}}$

$\mathrm{P}_{\mathrm{r}}$

$\mathrm{P}_{\mathrm{m}}$

For this study we have made a series of projections, resulting in estimates of $\mathrm{P}_{\mathrm{s}}, \mathrm{P}_{\mathrm{n}}, \mathrm{P}_{\mathrm{r}}$, and $\mathrm{P}_{\mathrm{m}}$ from 2000 to 2100 for all countries. We relied on projection software of the World Bank, which is readily available and easy to use, but in principle the same exercise could have been undertaken with UN or other standard projection packages. Global and regional estimates were obtained by aggregating country-level projections. 
Figure 1 presents the projection variants for the South. In the standard projection, population size grows from 4.9 billion in 2000 to 8.9 billion in 2100 , an 81 percent increase. Removing the very small migration effect gives essentially the same results, but eliminating the fertility effect reduces the projected population in 2100 to 7.8 billion. Finally, removing the role of declining mortality as well after 2000 reduces future growth further to its momentum level, yielding 6.8 billion in 2100 . The differences between the successive projections provide an indication of the role of the different factors. The momentum inherent in the current young age structure of the South is clearly the largest component.

Figure 2 presents the same set of projection variants for the North. Differences between the variants are smaller than in the South. The replacement

Figure 1 Population projection variants for the South

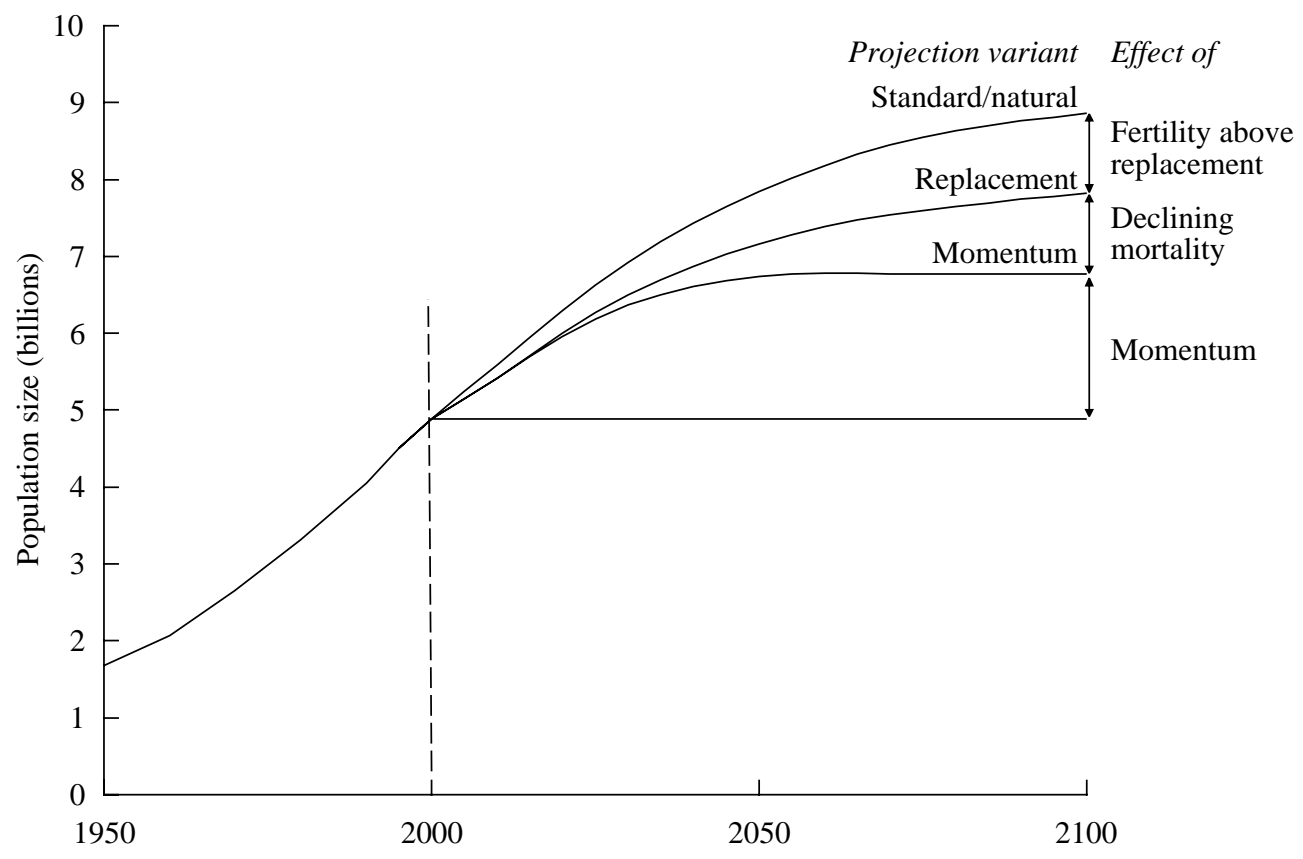

Source: See text. 
Figure 2 Population projection variants for the North

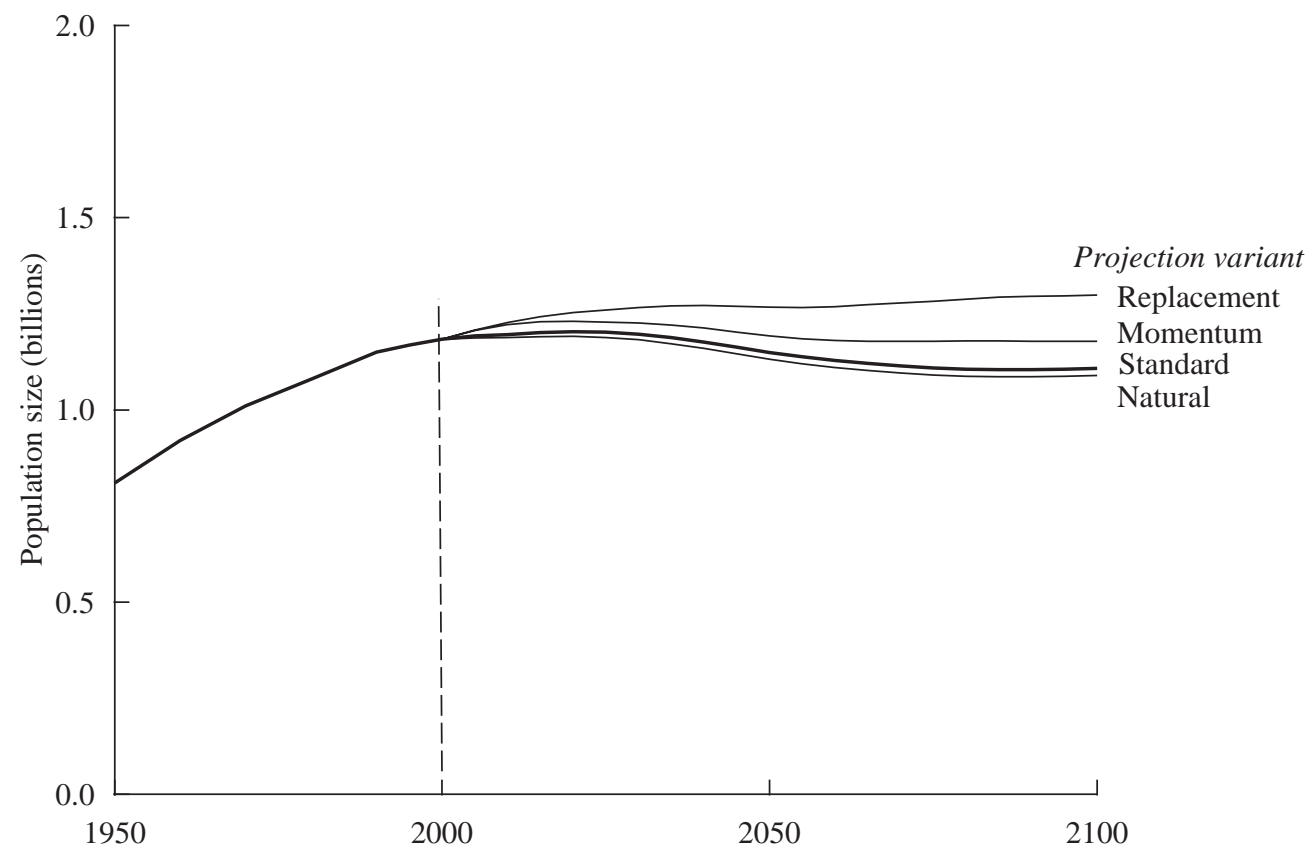

Source: See text.

projection gives a population total of 1.30 billion in 2100, a slight increase over the 2000 population size of 1.18 billion. This increase is almost entirely attributable to declining mortality, because momentum is zero. The natural projection ends up at 1.09 billion, significantly below the replacement projection because fertility is below the replacement level. A very modest level of net immigration leaves the standard projection (1.11 billion) slightly higher than the natural projection, but still below the 2000 population size.

The percent change in population growth between 2000 and 2100 from these projection variants, for the North and South as well as for the world and all major regions, is shown in Figure 3.

In order to directly compare the contributions of the different factors to future population growth, a set of factor "multipliers" are calculated. Each factor 
Figure 3 Population projection variants 2000-2100, by region

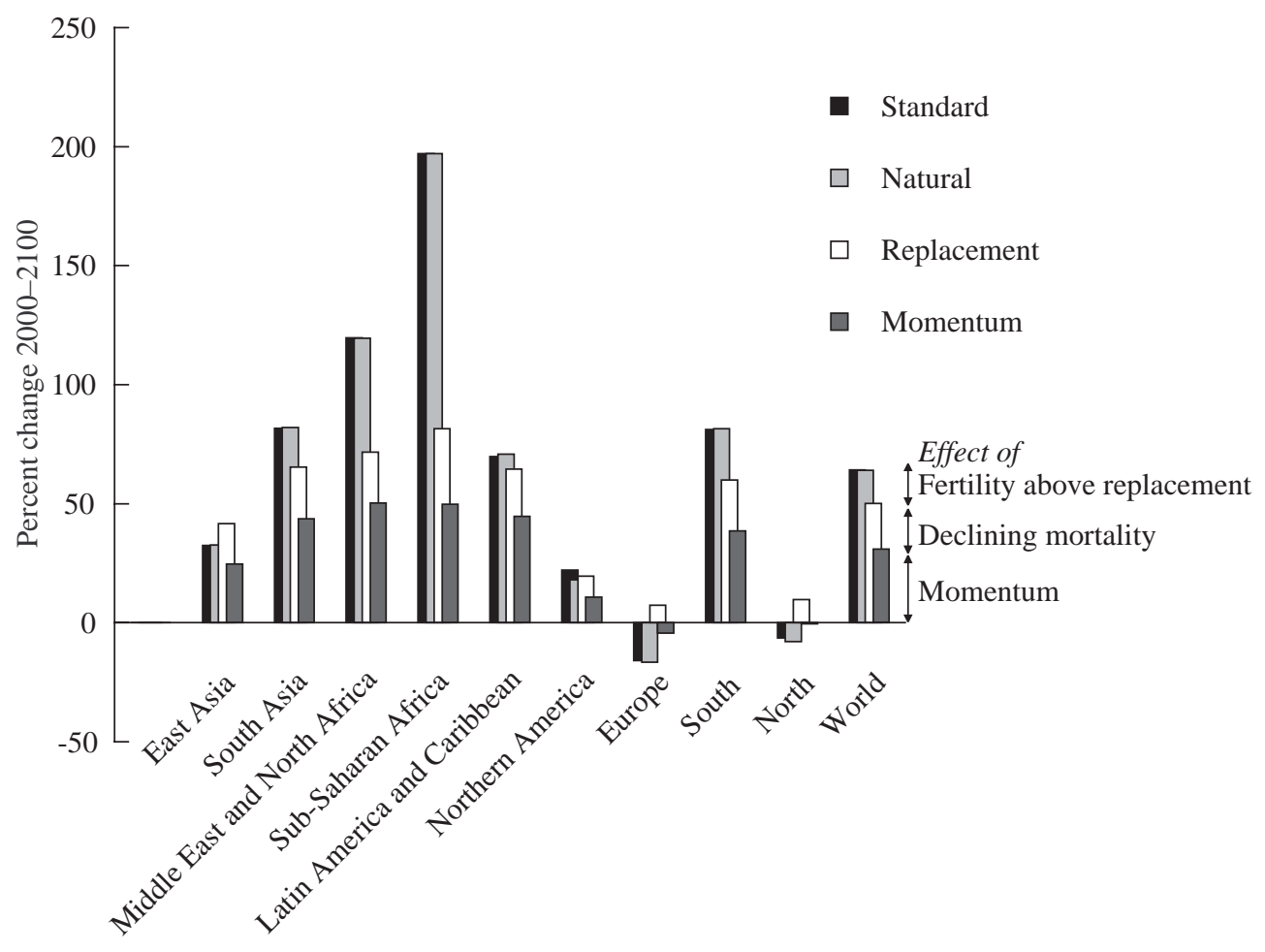

multiplier equals the ratio of the estimated population with and without the component at a future point in time:

$$
\begin{array}{ll}
\text { Immigration multiplier } & \mathrm{M}_{\mathrm{i}}=\mathrm{P}_{\mathrm{s}} / \mathrm{P}_{\mathrm{n}} \\
\text { Fertility multiplier } & \mathrm{M}_{\mathrm{f}}=\mathrm{P}_{\mathrm{n}} / \mathrm{P}_{\mathrm{r}} \\
\text { Mortality multiplier } & \mathrm{M}_{\mathrm{d}}=\mathrm{P}_{\mathrm{r}} / \mathrm{P}_{\mathrm{m}} \\
\text { Momentum multiplier } & \mathrm{M}_{\mathrm{m}}=\mathrm{P}_{\mathrm{m}} / \mathrm{P}
\end{array}
$$

where P represents the population size in 2000.

The combined effect of all factors is responsible for the population growth in the standard projection ${ }^{4}$ :

$$
P_{s}=M_{i} M_{f} M_{d} M_{m} P
$$


For example, for the South for the period 2000-2100, $\mathrm{M}_{\mathrm{i}}=1.0, \mathrm{M}_{\mathrm{f}}=1.13, \mathrm{M}_{\mathrm{d}}=$ $1.15, \mathrm{M}_{\mathrm{m}}=1.39$, and $\mathrm{P}_{\mathrm{s}}=1 \times 1.13 \times 1.15 \times 1.39 \times \mathrm{P}=1.81 \times \mathrm{P}$, implying an 81 percent increase in population over the next century (i.e. from $\mathrm{P}=4.9$ to $\mathrm{P}_{\mathrm{s}}=8.9$ billion). Table 1 presents projected population by region, as well as estimates of the multipliers for the period 2000 to 2100 . Multipliers can also be calculated for any year during the projection period, but this option is not pursued here.

The results in Figure 3 and Table 1 show wide variation among regions in the contributions of the different factors to growth over the next century. A few findings are noteworthy:

-Momentum is the largest component of future growth in the world and all regions except in Europe (where the age structure has aged sufficiently in recent decades so that momentum is slightly negative) and in sub-Saharan Africa

Table 1 Population projections for 2000 and 2100 and factor multipliers for migration, fertility, mortality, and momentum to 2100

\begin{tabular}{|c|c|c|c|c|c|c|}
\hline & \multicolumn{2}{|c|}{$\begin{array}{c}\text { Projected population } \\
\text { (billion) }\end{array}$} & \multicolumn{4}{|c|}{ Multiplier } \\
\hline & 2000 & 2100 & Migration & Fertility & Mortality & Momentum \\
\hline East Asia & 2.04 & 2.70 & 1.00 & 0.94 & 1.14 & 1.25 \\
\hline South Asia & 1.48 & 2.69 & 1.00 & 1.10 & 1.15 & 1.44 \\
\hline $\begin{array}{l}\text { Middle East and } \\
\text { North Africa }\end{array}$ & 0.33 & 0.73 & 1.00 & 1.28 & 1.14 & 1.50 \\
\hline Sub-Saharan Africa & 0.67 & 1.98 & 1.00 & 1.64 & 1.21 & 1.50 \\
\hline $\begin{array}{l}\text { Latin America and } \\
\text { Caribbean }\end{array}$ & 0.52 & 0.88 & 0.99 & 1.04 & 1.14 & 1.45 \\
\hline Northern America & 0.31 & 0.37 & 1.03 & 0.99 & 1.08 & 1.11 \\
\hline Europe & 0.73 & 0.61 & 1.01 & 0.78 & 1.12 & 0.96 \\
\hline South & 4.89 & 8.86 & 1.00 & 1.13 & 1.15 & 1.39 \\
\hline North & 1.18 & 1.11 & 1.02 & 0.84 & 1.10 & 1.00 \\
\hline World & 6.07 & 9.96 & 1.00 & 1.09 & 1.15 & 1.31 \\
\hline
\end{tabular}

Source: Based on World Bank 1998 
(where high fertility is the dominant factor). The momentum multiplier ranges from 1.50 in sub-Saharan Africa and the Middle East and North Africa to 0.96 in Europe. For every region in the South except sub-Saharan Africa, momentum is a larger contributor to growth than all other factors combined.

-Migration, as currently projected, is a minor factor even in Northern America, where $\mathrm{M}_{\mathrm{i}}$ is just 1.03 .

- The multipliers for fertility, mortality, and momentum are larger in subSaharan Africa than in any other region. As a result, future growth in this region (+196 percent) is projected to be much higher than elsewhere.

- The fertility multiplier exceeds one in the world and in most developing regions, but it is less than one (implying a negative impact on population growth) in Europe, Northern America, and East Asia, areas where fertility is currently below replacement.

Before proceeding, we comment briefly on the order in which the factors are removed in the successive projections from which the different multipliers are obtained. In principle, the contributions of fertility, mortality, and migration could be removed in any order, although the additional projections required would be substantial. In any case, the order has little or no effect in two cases. The momentum multiplier is not affected because it would always be the residual after the other effects are estimated. The generally small migration multiplier is also little affected because there is limited interaction with the other factors. On the other hand, the fertility and mortality multipliers are affected by the order in which they are removed. The reason is that, as noted earlier, the level of replacement fertility depends in part on the mortality that occurs up to the average age at childbearing. As a result, effects of changes in mortality below these ages are incorporated in the fertility multiplier as defined here, and the corresponding mortality multiplier is only affected by improvements in mortality above the mean age at childbearing. Reversing the order in which these two factors are removed therefore would result in a somewhat larger mortality multiplier and a somewhat 
smaller fertility multiplier. The choice of the particular order used here was based on two considerations. First, this order leads to very simple analytic equations for estimating the components of growth, as will be demonstrated below. Second, analysis of different population projections for policy purposes almost always involves alternative assumptions regarding future trends in fertility and/or migration, rather than in mortality or momentum, which are taken as given. For example, the UN and the World Bank projections have emphasized variants based on alternative future trends in fertility.

\section{Alternative estimates of the Population GROWTH COMPONENTS}

The preceding analysis has documented large variations in future increases in the population sizes of regions and attributed these variations to differences in four demographic factors. The estimation of these components of growth and the corresponding factor multipliers required the making of new sets of projections. Although the preparation of population projections has become simpler because of improved computer technology, it is still a cumbersome procedure, and few demographers let alone policymakers routinely make projections. To overcome this obstacle we now derive a set of simple analytic expressions to estimate the size of different factor multipliers at the end of the demographic transition from readily available measures of fertility, mortality, and age structure. These expressions will be derived initially for female populations. To simplify the presentation below, the results for the momentum multiplier will be examined first.

\section{Momentum}

Previous research on the demographic determinants of population momentum has resulted in a simple equation for estimating the momentum multiplier for the female population at the end of the transition (Kim and Schoen 1997; Preston 1986), 


$$
\mathrm{M}_{\mathrm{m}}=\mathrm{A} / \mathrm{A}_{\mathrm{m}}
$$

where A represents the proportion of females under age 30 at the beginning of the projection period (i.e., 2000) and $\mathrm{A}_{\mathrm{m}}$ is this same proportion at the end of the transition in a momentum projection (i.e., a projection with fertility at replacement, mortality fixed, and migration zero throughout). In 2000, for example, 59.3 percent of the female population of the South is expected to be under age 30, so that $A=0.593$. $A_{m}$ can be estimated as equal to 0.42 using a model mortality life table for a female life expectancy of 66 years in 2000.5 According to this equation the momentum multiplier therefore equals 1.41 (.593/.420). As expected, this is virtually the same as the estimate of 1.40 obtained from the actual projection to the end the transition. In general, given levels of current mortality by age (and hence $\mathrm{A}_{\mathrm{m}}$ ), the population momentum inherent in the age structure is directly proportional to the proportion of females under age 30 at the beginning of the projection.

\section{Mortality}

An equation for the mortality multiplier is readily derived from a variant of the preceding momentum multiplier equation. Since this equation also applies when mortality declines over the course of the projection, it follows that

$$
\mathrm{M}_{\mathrm{d}}=\mathrm{A}_{\mathrm{m}} / \mathrm{A}_{\mathrm{r}}
$$

where $A_{r}$ is the proportion of females under 30 at the end of the replacement projection (and $A_{m}$ is again determined by the mortality level in the momentum projection). At the high life expectancies that are projected to prevail at the end of the transition, $\mathrm{A}_{\mathrm{r}}$ is closely approximated by $30 / \mathrm{L}_{\mathrm{r}}$ where $\mathrm{L}_{\mathrm{r}}$ is the female life expectancy at the end of the transition in the replacement projection. ${ }^{6}$ Therefore

$$
\mathrm{M}_{\mathrm{d}}=\mathrm{L}_{\mathrm{r}} \mathrm{A}_{\mathrm{m}} / 30
$$

As might be expected, the mortality multiplier is a direct function of $\mathrm{L}_{\mathrm{r}}$. 


\section{Fertility}

The fertility multiplier is determined by the extent to which fertility differs from the replacement level over the course of the projection. Projections typically assume that fertility will decline (or rise) from its level in 2000 to the replacement level over the next few decades. If the number of years before fertility reaches replacement equals $y$ and the average proportional deviation from replacement during these y years equals d, then the fertility multiplier can be approximated $^{7}$ by

$$
M_{f}=(1+d)^{y / 30}
$$

This equation predicts that if fertility averages 50 percent above the replacement level over a 30-year period (i.e., $\mathrm{d}=0.5$ and $\mathrm{y}=30$ ) then $\mathrm{M}_{\mathrm{f}}=1.5$, implying a 50 percent inflation of the population at the end of the transition due to this deviation from replacement. In countries that remain at replacement throughout the projection, $\mathrm{d}=0$ and as a result $\mathrm{M}_{\mathrm{f}}=1.0$.

\section{Migration}

This multiplier is close to one for most populations. In a small number of countries the effect from migration is substantial, but the reasons are countryspecific and no attempt will be made to capture them in an equation.

\section{A SYNTHESIS}

The preceding equations can be combined to relate long-range future population growth to its demographic determinants. Ignoring migration, we focus on the factors driving replacement and natural growth.

\section{Replacement growth}

The ratio of population sizes at the beginning and end of the replacement projection will be called the replacement growth multiplier $\mathrm{PM}_{\mathrm{r}}$. It equals the 
product of the mortality and momentum multipliers:

$$
P M_{r}=M_{d} M_{m}
$$

Substitution of the equations for the different factor multipliers yields, for the female population,

$$
\mathrm{PM}_{\mathrm{r}}=\mathrm{L}_{\mathrm{r}} \mathrm{A} / 30
$$

In other words, replacement growth over the course of the transition is determined by just two factors: life expectancy at the end of the transition and the proportion of the female population under age 30 at the start of the projection. A comparison of the values of $\mathrm{PM}_{\mathrm{r}}$ estimated from this equation with the values obtained directly from the World Bank projections for 152 populations with sizes over 1 million produced an excellent fit $\left(\mathrm{R}^{2}=0.998\right)$.

This equation is further simplified if one assumes — as the UN and World Bank do - that all populations will have the same level of life expectancy at the end of the transition. In that case the only cause of variation in replacement growth is variation in the initial age structure as measured by A. With the World Bank assumption of $\mathrm{L}_{\mathrm{r}}=90$ years, $\mathrm{PM}_{\mathrm{r}}$ simply equals $3 \times \mathrm{A}$, and for the $\mathrm{UN}$ assumption of $\mathrm{L}_{\mathrm{r}}=92.5, \mathrm{PM}_{\mathrm{r}}$ equals $92.5 \times \mathrm{A} / 30$.

To illustrate an application of this equation, Table 2 gives the proportion of females under age 30 in 2000 and the $\mathrm{PM}_{\mathrm{r}}$ values obtained from actual replacement projections. The replacement multipliers, estimated as 3 x A for a life expectancy of 90 years, are in good agreement with the projection results. It is now a simple matter to calculate the replacement multiplier for a different level of life expectancy, by substituting this new level in the equation above. This is illustrated in the last column of Table 2, where female life expectancy at the end of the transition is set at 100 years. As expected, the replacement multipliers are all higher than they are with a life expectancy of 90 years. For example, for the world this multiplier increases from 1.65 to 1.83 as life expectancy rises from 90 to 100 years. 


\section{Natural growth}

The ratio of population sizes at the beginning and end of the natural projection will be called the natural growth multiplier $\mathrm{PM}_{\mathrm{n}}$. It equals the product of the fertility, mortality, and momentum multipliers:

$$
P M_{n}=M_{f} M_{d} M_{m}
$$

Substitution of the equations for the different multipliers yields for the female population

$$
\mathrm{PM}_{\mathrm{n}}=(1+\mathrm{d}){ }^{\mathrm{y} / 30} \mathrm{~L}_{\mathrm{r}} \mathrm{A} / 30
$$

According to this equation, natural growth of the female population over the remainder of the transition depends on the extent and duration of deviations from replacement fertility as measured by the multiplier $M_{f}$, on the level of life

Table 2 Percent of females aged less than 30 years in 2000, and replacement growth multiplier $\mathrm{PM}_{\mathrm{r}}$ to the end of the transition, by region, calculated from projections and estimated from a model for female population

\begin{tabular}{lcccc}
\hline & $\begin{array}{c}\text { Percent of } \\
\text { females less than } \\
\text { age 30 in 2000 }\end{array}$ & $\begin{array}{c}\text { Projection } \\
\text { estimate of PM }\end{array}$ & \multicolumn{2}{c}{\begin{tabular}{c} 
Model estimate of PM \\
\cline { 3 - 5 }
\end{tabular}} \\
\cline { 4 - 5 } East Asia & 51.2 & 1.53 & 1.54 & Life expectancy \\
South Asia & 62.3 & 1.87 & 1.87 & 2.71 \\
Middle East and North Africa & 63.1 & 1.88 & 1.89 & 2.10 \\
Sub-Saharan Africa & 70.9 & 2.11 & 2.13 & 2.36 \\
Latin America and Caribbean & 58.3 & 1.75 & 1.75 & 1.94 \\
Northern America & 40.1 & 1.22 & 1.20 & 1.34 \\
Europe & 36.6 & 1.09 & 1.10 & 1.22 \\
South & 59.3 & 1.78 & 1.78 & 1.98 \\
North & 37.3 & 1.12 & 1.12 & 1.24 \\
World & 54.9 & 1.65 & 1.65 & 1.83 \\
\hline
\end{tabular}

Source: Based on World Bank 1998 
expectancy at the end of the transition $\left(\mathrm{L}_{\mathrm{r}}\right)$, and on the initial age structure (A). A comparison of the values of $\mathrm{PM}_{\mathrm{n}}$ obtained from this equation with the actual World Bank projections for 152 populations again produced an excellent fit $\left(\mathrm{R}^{2}=0.998\right)$. If we accept the World Bank's assumption that female life expectancy at the end of the transition will equal 90 years in all countries, then the factors explaining variations in future natural growth are reduced to just two: the fertility multiplier $\left(\mathrm{M}_{\mathrm{f}}\right)$ and the initial proportion of females under age $30(\mathrm{~A})$.

For most practical purposes these equations for estimating replacement and natural growth in the female population provide simple but reasonably accurate tools for analyzing variations in growth over the remainder of the transition and for estimating the impact of changes in the factors on future population growth. A similar set of multiplier equations can be derived for the male population (see Appendix). The male multipliers are usually close to the corresponding values for the female population.

\section{THE END OF THE TRANSITION}

As noted, existing projections of the UN and World Bank assume that at the end of the transition all countries will have fixed levels of fertility and mortality and zero migration. These are convenient assumptions, because they are simple to implement in projection exercises for large numbers of countries and they lead to zero growth. In reality, however, there are likely to be variations in levels of fertility, mortality, and migration among countries for the indefinite future.

In addition, it seems unlikely that the assumed long-range trends will prevail on average. The assumption of no migration is least problematic on the regional and global level because the effects of migration on the population size of these aggregates is modest. In contrast, the assumption that life expectancy will reach some maximum is questionable. In projections made in the 1960s and 1970s the UN and World Bank also assumed a maximum to prevail, but at lower levels. In successive revisions of its projections the UN has raised this maximum every 
few years, from 74 years in the 1963 assessment to 90 years (both sexes) in the 1998 assessment. It seems desirable not to impose a limit on life expectancy and let it rise slowly over time. Similarly it seems doubtful whether fertility will level off exactly at the replacement level on average. Again it is difficult to predict what the actual level might be, but recent experience in countries that have reached the end of their transitions suggests that fertility might well drop somewhat below replacement.

Presumably, one motivation for making these simplifying assumptions is that they lead to zero growth in population size. But if this is indeed an objective, then an alternative set of assumptions can achieve it. Specifically, zero growth can be achieved with rising life expectancy and below-replacement fertility, if these factors offset one another. The precise level of fertility that would achieve zero growth would depend on the level of life expectancy and on the rate at which it is rising, and it might vary slightly over time. But such a scenario is arguably a more realistic one for the end of the transition. It should be emphasized that the age structure would not stabilize under these alternative conditions, and populations would continue to age indefinitely.

\section{CONCLUSION}

The most recent population projections of the World Bank and UN expect the world population to grow from 5.9 billion today to about 10 billion in 2100 . Expansion is expected to be most rapid in the next few decades in Africa, South and West Asia, and Latin America. The growth in these regions is attributable to three demographic factors: 1) fertility remains above the replacement level, 2) mortality continues to decline, and 3 ) the proportion of the population under age 30 is relatively high. Even if fertility could be brought to the replacement level immediately, substantial growth is inevitable (from 4.9 billion in 2000 to 7.8 billion in 2100 according to the replacement projection) because of population momentum. In contrast, populations in the developed countries of the North will 
either grow little or decline, because fertility is at or below the replacement level, mortality is already low, and the age structures are no longer young.

The preceding analysis has measured the contributions of each of these factors for the world and its major regions. The momentum inherent in the current young age structure was found to be the main component of future growth in all regions except Europe (where the population has aged sufficiently in recent decades so that momentum is slightly negative) and sub-Saharan Africa (where high fertility is the dominant factor).

\section{APPENDIX}

The male factor multipliers (identified by the superscript') are derived from the female multipliers (without superscripts), except for migration

$$
\begin{aligned}
& M^{\prime}{ }_{m}=M_{m} S R L^{\prime}{ }_{m} / L_{m} \\
& M^{\prime}{ }_{d}=M_{d} L_{m} L_{r}^{\prime} /\left(L_{m}^{\prime} L_{r}\right) \\
& M^{\prime}{ }_{f}=M_{f}
\end{aligned}
$$

where $\mathrm{L}_{\mathrm{m}}$ and $\mathrm{L}_{\mathrm{r}}$ refer to the life expectancy at birth at the end of the momentum and replacement projections respectively. $S$ represents the sex ratio at birth (number of male births per female birth), and $\mathrm{R}$ equals the ratio of female to male population at the beginning of the projection. Substitution gives

$$
\mathrm{PM}_{\mathrm{n}}^{\prime}=(1+\mathrm{d})^{\mathrm{y} / 30} \mathrm{~L}_{\mathrm{r}} \text { A S R / } 30
$$

\section{Notes}

1 In this study the end of the transition is defined as the time when the birth rate declines to equal the death rate.

2 Assuming mortality reaches a fixed level and migration is absent. 
3 The term population momentum is sometimes used to refer to the future population growth that would occur if fertility were held at the replacement level, without modifying assumptions about trends in mortality and migration. This study follows the convention used in the technical demographic literature, which defines momentum as the future growth if fertility is set at replacement, while holding mortality constant and assuming no migration. Momentum is usually positive, but it can also be negative.

$4 \quad$ Similarly $\mathrm{P}_{\mathrm{n}}=\mathrm{M}_{\mathrm{f}} \mathrm{M}_{\mathrm{d}} \mathrm{M}_{\mathrm{m}} \mathrm{P}, \mathrm{P}_{\mathrm{r}}=\mathrm{M}_{\mathrm{d}} \mathrm{M}_{\mathrm{m}} \mathrm{P}$, and $\mathrm{P}_{\mathrm{m}}=\mathrm{M}_{\mathrm{m}} \mathrm{P}$

5 Because the population is stationary at the end of the transition, $\mathrm{A}_{\mathrm{m}}$ equals the proportion under age 30 in a model life table population at the mortality level prevailing during the momentum projection.

6 Replacing $\mathrm{L}_{\mathrm{r}}$ with 18 plus the life expectancy at age 18 gives a more accurate result at lower life expectancies.

7 If deviations from replacement fertility are constant throughout the y years, one would expect the multiplier to equal $(1+\mathrm{d})^{\mathrm{y} / \mathrm{T}}$ where $\mathrm{T}$ is the length of a generation (the term $1+\mathrm{d}$ equals the net reproduction rate). T generally is slightly below 30 years. However, in reality the deviations from replacement decline with time, which introduces a bias that can be captured by adding a correction factor $\mathrm{c}$ in this equation: $(1-\mathrm{r})^{\mathrm{y} / \mathrm{TC}}$. In the simple version of this equation that is used in the text, it is assumed that $\mathrm{T} \mathrm{x} \mathrm{c}=30$, with satisfactory results.

\section{References}

Keyfitz, Nathan. 1971. "On the momentum of population growth,” Demography 8 (1): 71-80. 
Kim, Young J. and Robert Schoen. 1997. "Population momentum expresses population aging," Demography 34 (3): 421-427.

Lutz, Wolfgang (ed.). 1996. The Future Population of the World: What Can We Assume Today? London: Earthscan Publications.

Preston, Samuel H. 1986. "The relation between actual and intrinsic growth rates," Population Studies 40 (3): 343-351.

United States Bureau of the Census. 1999. World Population Profile: 1998. Washington, DC: US Department of Commerce.

United Nations, Population Division. 1998a, World Population Projections to 2150. New York.

United Nations Department for Economic and Social Information and Policy Analysis, Population Division. 1998b. World Population Prospects: The 1998 Revision. Annex I: Demographic Indicators. New York.

World Bank. 1998. World Development Indicators 1998. Washington, DC. 


\title{
POLICY RESEARCH DIVISION WORKING PAPERS
}

\author{
Recent Back Issues
}

\section{7}

93 James F. Phillips, Fred N. Binka, Martin Adjuik, Alex Nazzar, and Kubaze Frank Adazu, "The determinants of contraceptive innovation: A case-control study of family planning acceptance in a traditional African society."

*94 John Bongaarts and Sajeda Amin, "Prospects for fertility decline and implications for population growth in South Asia."

95 Barbara S. Mensch and Cynthia B. Lloyd, "Gender differences in the schooling experiences of adolescents in low-income countries: The case of Kenya."

96 Martin Brockerhoff and Ellen Brennan, "The poverty of cities in the developing world."

*97 Carol E. Kaufman, "Reproductive control in South Africa."

*98 John Bongaarts, "Trends in unwanted childbearing in the developing world."

99 Mary Arends-Kuenning, "How do family planning workers' visits affect women's contraceptive behavior in Bangladesh?"
100 Mark R. Montgomery and Cynthia B. Lloyd, "Excess fertility, unintended births, and children's schooling."

101 Mary Arends-Kuenning, "The equity and efficiency of doorstep delivery of contraceptives in Bangladesh."

*102 Sajeda Amin, Ian Diamond, Ruchira T. Naved, and Margaret Newby, "Transition to adulthood of female factory workers: Some evidence from Bangladesh.”

*103 Margaret E. Greene and Ann E. Biddlecom, "Absent and problematic men: Demographic accounts of male reproductive roles."

104 Michael P. Todaro, "Urbanization, unemployment, and migration in Africa: Theory and policy."

105 Geoffrey McNicoll, "Population and poverty: A review and restatement."

\footnotetext{
* No longer available
} 
106 Sajeda Amin and Gilda Sedgh, "Incentive schemes for school attendance in rural Bangladesh."

107 Martin Brockerhoff and Paul Hewett, "Ethnicity and child mortality in subSaharan Africa."

108 Ann E. Biddlecom and Bolaji M. Fapohunda, "Covert contraceptive use: Prevalence, motivations, and consequences."

109 John Bongaarts and Griffith Feeney, "On the quantum and tempo of fertility."

110 Barbara S. Mensch, Daniel Bagah, Wesley H. Clark, and Fred Binka, "The changing social environment for adolescents in the Kassena-Nankana District of northern Ghana: Implications for reproductive behavior."

111 Martin Brockerhoff and Ann Biddlecom, "Migration, sexual behavior, and HIV diffusion in Kenya."

112 Zeba A. Sathar and John B. Casterline, "The onset of fertility transition in Pakistan."

113 Geoffrey McNicoll, "Government and fertility in transitional and post-transitional societies."
114 John Bongaarts, "Fertility and reproductive preferences in post-transitional societies."

115 Fiona Steele, Sajeda Amin, and Ruchira T. Naved, "The impact of an integrated micro-credit program on women's empowerment and fertility behavior in rural Bangladesh."

*116 Cynthia B. Lloyd, Barbara S. Mensch, and Wesley H. Clark, "The effects of primary school quality on the educational participation and attainment of Kenyan girls and boys."

117 Sajeda Amin and Cynthia B. Lloyd, "Women's lives and rapid fertility decline: Some lessons from Bangladesh and Egypt."

118 James F. Phillips and Mian Bazle Hossain, "The impact of family planning household service delivery on women's status in Bangladesh."

119 Mark R. Montgomery and John B. Casterline, "Social networks and the diffusion of fertility control."

* No longer available 
120 John Bongaarts, "The fertility impact of changes in the timing of childbearing in the developing world."

121 James F. Phillips, Wendy L. Greene, and Elizabeth F. Jackson, "Lessons from community-based distribution of family planning in Africa."

122 Mark R. Montgomery, "Mortality decline and the demographic response: Toward a new agenda."

123 Mark R. Montgomery, Mary ArendsKuenning, and Cem Mete, "The quantity-quality transition in Asia."
124 Barbara S. Mensch, Wesley H. Clark, Cynthia B. Lloyd, and Annabel S. Erulkar, "Premarital sex and school dropout in Kenya: Can schools make a difference?"

125 John Bongaarts and Rodolfo A. Bulatao, "Completing the demographic transition." 